\title{
DIAGNÓSTICO DA FRAGILIDADE AMBIENTAL NA BACIA HIDROGRÁFICA DO RIO SANTO ANTÔNIO, MS: SUBSÍDIO AO ZONEAMENTO AMBIENTAL
}

\author{
DIAGNOSING ENVIRONMENTAL FRAGILITY ON THE \\ HYDROGRAPHIC BASIN OF SANTO ANTÔNIO RIVER, \\ MS: SUBSIDY TO ENVIRONMENTAL ZONING \\ DIAGNOSTIC DE LA FRAGILITE ENVIRONNEMENTALE \\ DU BASSIN VERSANT DE LA RIVIERE SANTO ANTONIO: \\ SUBVENTION POUR LE ZONAGE ENVIRONNEMENTAL
}

Cleiton Messias Rodrigues Abrão - Universidade Federal da Grande

Dourados - Dourados - Mato Grosso do Sul -Brasil

cleiton.geografo@yahoo.com.br

Vitor Matheus Bacani - Universidade Federal de Mato Grosso do

Sul - Três Lagoas - Mato Grosso do Sul - Brasil

vitor.bacani@ufms.br

\section{Resumo}

Este trabalho tem por objetivo identificar os níveis de fragilidade ambiental da Bacia Hidrográfica do rio Santo Antônio e propor um zoneamento ambiental preliminar. Para isso, utilizou-se a metodologia de Ross (1994 e 2012) da fragilidade potencial e ambiental, apoiada em dados de sensoriamento remoto e de geoprocessamento. Foi utilizada imagem de satélite Landsat 8/0LI - 2014 para o mapeamento do uso da terra e dados do projeto GeoMS sobre a cobertura vegetal. A fragilidade ambiental foi elaborada a partir da combinação dos mapas de fragilidade potencial com o mapa temático de uso e cobertura da terra de 2014. 0 s resultados demonstram que há predomínio de média fragilidade ambiental $(74,81 \%)$, associada à ocupação majoritária da bacia pela pastagem, que ocupa $52,1 \%$ da área. Há também conflitos em Áreas de Preservação Permanente (APP) ocupadas irregularmente por pastagem e agricultura. Considerando a situação em que se encontra a bacia foi proposto um zoneamento ambiental preliminar, com diretrizes de uso e ocupação da área de modo sustentável e com recomendações e restrições de uso em áreas mais frágeis, bem como proposições de recuperação das áreas que se encontram degradadas.

Palavras-chave: Fragilidade ambiental, geoprocessamento, uso da terra, bacia hidrográfica do Rio Santo Antônio.

\section{Abstract}

This study aims to identify the environmental fragility of the Hydrographic Basin of Santo Antônio River, and to suggest an initial environmental zoning. For this purpose, it was used Ross's (1994 and 2012) methodology of potential and environmental fragility supported by remote sensing data as well as geoprocessing. It was used image from Landsat satellite 8/OLI - 2014 for Land use mapping and project GeoMS data about land cover. The environmental fragility was developed from the combination of potential fragility maps and theme maps of land use and cover of 2014. The results have shown that there is predominance of medium environmental fragility $(74.81 \%)$, associated to the major occupation of the basin by pasture, which occupies $52.1 \%$ of the area. There are also Permanent Preservation Area (PPA) improperly occupied with pasture and agriculture. 
Giving the situation in which the basin is found, it was proposed an initial environmental planning with use and occupation guidelines of the area in a sustainable manner with recommendations and limitations of use in vulnerable areas, such as proposition of recovering degrades areas.

Keywords: Environmental fragility, geoprocessing, land use, basin of Santo Antônio River.

\section{Résumé}

L'objectif de cette étude est identifier la fragilité environnementale du bassin de la rivière Santo Antônio et de proposer un zonage environnemental préliminaire. Nous adoptons une approche méthodologique de la fragilité environnementale (Ross,1994 et 2012), sur la base de données de télédétection et géomatique. Nous avons utilisé satellite Landsat 8 / OLI (I'année 2014) pour cartographier l'occupation des sols et données de projet GeoMS sur la couverture végétale. La fragilité de l'environnement a été développé à partir de la combinaison des cartes thématiques (fragilité potentielle et occupation du sol en 2014). Les résultats ont montré qu'il y a une prédominance de la moyenne fragilité environnementale $(74,81 \%)$. Ceci est associé à des pâturages qui occupe la majeure partie de la superficie du bassin $(52,1 \%)$. II y a aussi des conflits dans les zones de préservation permanents qui sont irrégulièrement occupés par le pâturage et l'agriculture. Compte tenu de la situation, il a été proposé un zonage environnemental préliminaire avec les directives d'utilisation et de l'occupation de la zone durable avec des recommandations et des restrictions d'utilisation dans les zones fragiles, ainsi que la proposition d'une zone de récupération des terres dégradées.

Mots-clés: Fragilité Environnementale, Géomatique, L'utilisation des Terres, Bassin de la Rivière Santo Antônio.

Introdução

A análise da fragilidade dos grandes sistemas naturais, em especial bacias hidrográficas, vem sendo utilizada como subsídio para o zoneamento e ordenamento físico territorial dessas áreas naturais, consideradas unidades de planejamento integrado. Estudos nessa perspectiva têm por finalidade identificar as fragilidades e potencialidades dos ambientes naturais e propor uma melhor forma de uso e ocupação do território, de acordo com as características de cada lugar.

Pensando desse modo, Ross (1994) elaborou um roteiro teórico metodológico embasado na teoria ecodinâmica (Tricart, 1977) para avaliação da fragilidade potencial e fragilidade ambiental ou emergente dos sistemas naturais, que vêm sendo usados e readaptados de acordo com cada local, a fim de orientar o planejamento e zoneamento ambiental. Segundo Kawakubo et al. (2005) a fragilidade potencial é a vulnerabilidade natural dos componentes físicos dos ambientes naturais sem intervenção antrópica, como solo, declividade, geologia etc. Já a fragilidade ambiental é definida, segundo Kawakubo et al. (2005), como a integração entre a fragilidade potencial e os tipos de uso da terra e cobertura vegetal classificados de acordo com o grau de proteção ao solo. São definidas cinco classes de fragilidade e pesos, sendo divididas em: muito fraca (1), fraca (2), média (3), forte (4) e muito forte (5). 
A partir desses conceitos, várias pesquisas vêm sendo realizadas utilizando e aprimorando essa metodologia de acordo com as características físico-naturais e antrópicas de cada área de estudo (Manfré et al., 2013; Cabral et al., 2011; Bacani; Luchiari, 2014). A adoção de outras variáveis para avaliação da fragilidade ambiental busca sempre melhorar os resultados e tornar o modelo o mais fiel possível à realidade. Assim como apresentado nos trabalhos de Pires et al. (2015) e Cabral et al. (2011) em suas respectivas áreas de estudo, há necessidade de utilização de outras variáveis e atribuição de pesos de acordo com as características de cada componente da paisagem (solo, litologia, relevo, biodiversidade etc.), o que contribuirá para identificação dos níveis de fragilidade.

Segundo Santos (2004), o zoneamento ambiental é a base para o planejamento ambiental, apresentando-se como uma estratégia importante para a gestão ambiental, com a espacialização das informações através de um mapa síntese, contendo zonas "homogêneas" e com certa similaridade entre os elementos da paisagem. As bacias hidrográficas são os recortes espaciais mais utilizados para elaboração de diretrizes de uso sustentável dos recursos naturais, sendo possível, nesses ambientes, observar as inter-relações existentes entre os componentes da paisagem (Ferreira; Piroli, 2016; Botelho; Silva, 2011). A bacia hidrográfica do rio Santo Antônio (BHRSA) se destaca por apresentar elementos paisagísticos muito heterogêneos e que, portanto, também demandam adaptações metodológicas para o estabelecimento de pesos de fragilidade.

A BHRSA apresenta aptidão para atividades agropecuárias, porém nos últimos anos essas áreas têm avançado sobre espaços naturais com remanescente de vegetação nativa e em Áreas de Preservação Permanente (APP), localizadas próximas aos mananciais. Contudo, ainda não há nenhum diagnóstico ambiental na escala geográfica para essa bacia hidrográfica. O rio Santo Antônio, principal rio da bacia, tem grande importância local, pois esse manancial é fonte de abastecimento público de água para os moradores da cidade de Guia Lopes da Laguna, situada próxima a sua foz com o rio Miranda. Além disso, o rio Santo Antônio é um dos principais afluentes do rio Miranda, cujas águas fluem em direção ao rio Paraguai, formando a principal rede de drenagem do Pantanal Sul-Mato-Grossense.

Adicionalmente há uma grande lacuna na literatura no que diz respeito a trabalhos voltados ao diagnóstico integrado das potencialidades 
e fragilidades do ambiente e que considerem as variáveis: riqueza da biodiversidade e potencial de inundação. Desse modo, este trabalho tem por objetivo identificar os níveis de fragilidade potencial e ambiental da BHRSA e propor um zoneamento ambiental em relação às características naturais e os tipos de uso da terra e cobertura vegetal.

\section{Materiais e Métodos}

\section{Área de estudo}

A BHRSA está localizada no sudoeste de Mato Grosso do Sul (MS), com uma área de aproximadamente 1.202 km² (Figura 1). Há quatro municípios com território dentro da bacia, Nioaque, Maracaju, Ponta Porã e Guia Lopes da Laguna, com destaque para o último, que abrange a maior parte da bacia e é o único com sede municipal dentro da mesma.

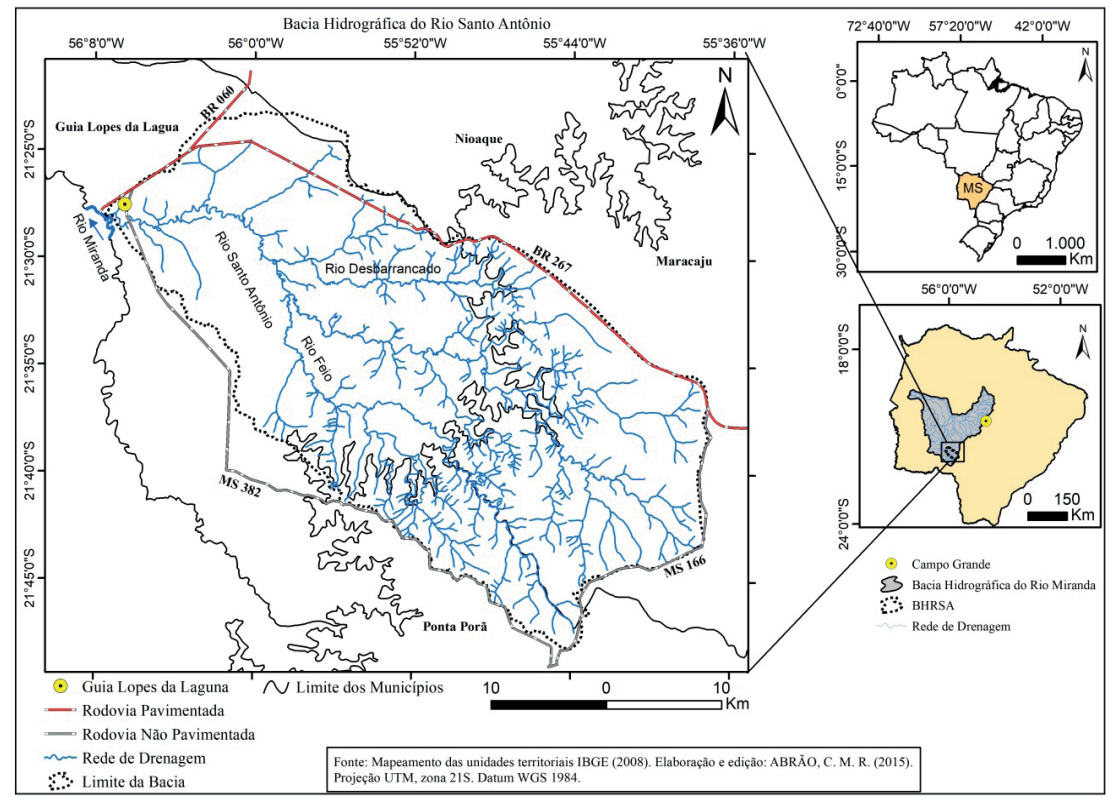

Figura 1 - Mapa de localização da área de estudo.

Fonte: Mapeamento das unidades territoriais IBGE (2008). 
Procedimentos metodológicos

Foi organizado um banco de dados geográficos no software ArcGIS 10.2 (ESRI, 2013) contendo materiais em formato vetorial e raster. Para elaboração da carta de fragilidade potencial foram selecionadas três variáveis do meio físico (Ross, 1994; 2012; Crepani et al., 2001) que representam os componentes físicos da paisagem, e uma de importância biológica para conservação da biodiversidade (Brasil, 2007), (Figura 2).

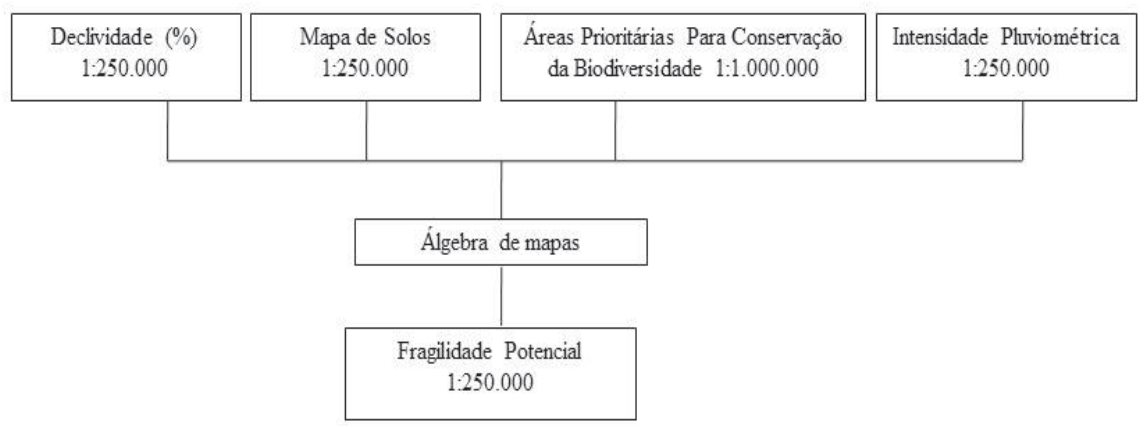

Figura 2 - Fluxograma metodológico para elaboração da Fragilidade Potencial.

Fonte: Elaboração dos autores (2015).

A declividade foi gerada a partir da imagem de radar SRTM (Valeriano, 2008) em valores definidos em porcentagem e reclassificada de acordo com Ross (2012). As áreas delimitadas como planície de inundação foram identificadas a partir da declividade menor que $2 \%$ e áreas próximas aos canais fluviais sujeitas a inundação. Os dados de solos foram extraídos do banco de dados do Sistema Interativo de Suporte ao Licenciamento Ambiental (SISLA [2014]) e elaborados pelo Macrozoneamento (Mato Grosso do Sul, 1989) na escala de 1:250.000. A intensidade pluviométrica foi calculada a partir de dados quantitativos de chuva, acumulados em oito estações próximas à área de estudo e coletados de 1970 a 2007, somando mais de 30 anos, que é o recomendado. 


\begin{tabular}{|c|c|c|}
\hline Nome da estação & Lat/Long & Média Anual (mm) \\
\hline Estação Jardim & s $21^{\circ} 26^{\prime} 25^{\prime \prime}$, w $56^{\circ} 05^{\prime} 24^{\prime \prime}$ & $1.287,4$ \\
\hline Estação Maracaju & s $21^{\circ} 37^{\prime} 02^{\prime \prime}$, w $55^{\circ} 08^{\prime} 11^{\prime \prime}$ & $1.395,9$ \\
\hline Estação Nioaque & s $21^{\circ} 08^{\prime} 58^{\prime \prime}$, w $55^{\circ} 49^{\prime} 27^{\prime \prime}$ & $1.152,6$ \\
\hline Estação Bonito & 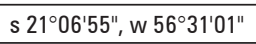 & 1.380 \\
\hline Estação Antônio João & s $22^{\circ} 11^{\prime} 08^{\prime \prime}$, w 5556'31" & 1.571 \\
\hline Estação Capão Bonito & s $21^{\circ} 10^{\prime} 53^{\prime \prime}$, w $54^{\circ} 44^{\prime} 38^{\prime \prime}$ & $1.293,5$ \\
\hline Estação Sidrolândia & s $22^{\circ} 06^{\prime} 32^{\prime \prime}$, w $56^{\circ} 31^{\prime} 35^{\prime \prime}$ & 1.325 \\
\hline Estação Bela Vista & s $22^{\circ} 06^{\prime} 32^{\prime \prime}$, w $56^{\circ} 31^{\prime} 35^{\prime \prime}$ & 1.325 \\
\hline
\end{tabular}

Quadro 1- Estações pluviométricas usadas para geração da intensidade pluviométrica.

Fonte: EMBRAPA CLIMA (2014).

Com os dados reunidos sobre a pluviosidade do entorno, realizou-se a interpolação desses dados através do método Inverse Distance Weight (IDW), disponível no ArcGIS. Porém, Ross (1994) não atribuiu peso de fragilidade a esta variável, sendo necessária uma adaptação metodológica, de acordo com Crepani et al. (2001).

As Áreas Prioritárias para Conservação da Biodiversidade foram elaboradas pelo Ministério do Meio Ambiente (BRASIL, 2007) para indicar áreas prioritárias à preservação da flora e fauna dos biomas brasileiros, e para a implantação de Unidades de Conservação (UC's). Os planos de informações (PIs) em formato vetorial foram convertidos em formato raster e reclassificados de acordo com os pesos de fragilidade atribuídos por Ross (1994; 2012). Logo em seguida, realizou-se a sobreposição ponderada (álgebra de mapas) de todos os temas, que resultou na fragilidade potencial, após a reclassificação das variáveis, conforme descrito na Tabela 1.

\begin{tabular}{ccccc}
\hline $\begin{array}{c}\text { Peso de Fragilidade } \\
\text { Potencial }\end{array}$ & Declividade (\%) & Solos & Áreas Prioritárias & $\begin{array}{c}\text { Intensidade } \\
\text { Pluviométrica }\end{array}$ \\
\hline 1 - Muito Fraca & $0-2$ & $\begin{array}{c}\text { Latossolo Vermelho; Latossolo } \\
\text { Vermelho Eutrófio; Latossolo Amarelo; } \\
\text { Latossolo Regolítico }\end{array}$ & $\begin{array}{c}\text { Insuficientemente } \\
\text { conhecida }\end{array}$ & $*$ \\
$2-$ Fraca & $2-15$ & $*$ & $*$ & 2 \\
3 - Média & $15-30$ & $*$ & $*$ & $*$ \\
$4-$ Forte & $30-50$ & $*$ & $*$ & $*$ \\
5 - Muito Forte & $>50$ & $\begin{array}{c}\text { Neossolo Quartzarênico; Neossolo } \\
\text { Litólico Luvissolo; Plintossolo; }\end{array}$ & Muito Alta & $*$ \\
5 - Muito Forte & $\begin{array}{c}<\text { em áreas de } \\
\text { planície fluvial }\end{array}$ & & & \\
\hline
\end{tabular}

Tabela 1 - Variáveis utilizadas para fragilidade potencial e seus respectivos pesos.

* Classe/Peso de fragilidade não definida por não ocorrer na área de estudo.

Fonte: Elaborado pelos autores (2015). 
O mapa de uso e cobertura da terra foi gerado através do método de classificação digital, denominado classificação supervisionada da imagem Landsat 8/OLI (Órbita/Ponto 225/75), no mês de abril de 2014, imagem obtida no site da Earth Explorer (USGS, 2014). Foram seguidos os procedimentos técnicos científicos de rotina de Processamento Digital de Imagem (PDI), descritos em Moreira (2007); Jensen (2009); Novo (2010) e Florenzano (2011; 2002): pré-processamento, realce e classificação. As imagens orbitais foram obtidas já pré-processadas pelo USGS (2014). O realce aplicado foi o contraste linear nas bandas 4B, 5G e 6R. Utilizou-se o classificador por região Bhatachayara disponível no software SPRING (Camara et al., 1996).

As fitofisionomias de cobertura vegetal foram identificadas de acordo com mapeamento de Silva et al. (2011), realizado para o estado de Mato Grosso do Sul, na escala de 1:100.000. O mapeamento de uso da terra e cobertura vegetal foi validado pelo Índice Kappa (Congalton, 1991), e a exatidão global pela coleta de 430 pontos distribuídos aleatoriamente sobre as classes temáticas, obtidos em trabalho de campo registrados via sistema GNSS (Global Navigation Satellite System) e complementarmente em imagens de alta resolução espacial (Google Earth, Bing). A acurácia do mapeamento foi de 0,75 , considerado muito bom, conforme parâmetros estabelecidos por Landis e Koch (1977). Para a elaboração da legenda do mapa de uso e cobertura da terra seguiu-se o padrão de cores definido pelo manual técnico de uso da terra elaborado pelo IBGE (2013). Foram definidas sete classes de uso e cobertura da terra e oito classes de cobertura vegetal, às quais foram atribuídos pesos de acordo com a metodologia de Ross (1994), com algumas adaptações para área de estudo, conforme descrito na Tabela 2. 


\begin{tabular}{|c|c|}
\hline Classe de uso da terra e cobertura vegetal & Grau de Proteção \\
\hline Pastagem & 3 (Média) \\
\hline Agricultura convencional & 5 (Muito Baixa) \\
\hline Agricultura conservacionista & 4 (Baixa) \\
\hline Corpos d'água & 5 (Muito Baixa) \\
\hline Área Úmida & 5 (Muito Baixa) \\
\hline Área Urbana & 5 (Muito Baixa) \\
\hline Silvicultura & 3 (Média) \\
\hline Savana com Floresta de Galeria & 2 (Alta) \\
\hline Savana sem Floresta de Galeria & 2 (Alta) \\
\hline Savana/Floresta Estacional Decidual Submontana & 2 (Alta) \\
\hline Savana Arborizada & 2 (Alta) \\
\hline Savana Arborizada Gramíneo Lenhosa & 2 (Alta) \\
\hline Savana Florestada & 2 (Alta) \\
\hline Floresta Aluvial & 2 (Alta) \\
\hline Vegetação Secundária de Savana & 3 (Média) \\
\hline
\end{tabular}

Tabela 2 - Grau de fragilidade atribuído às classes de uso da terra e cobertura vegetal.

Fonte: Adaptado de Ross (1994).

O mapa de fragilidade ambiental foi elaborado com base nos mapas temáticos de fragilidade potencial, uso da terra e cobertura vegetal (Figura 3). O mapa de uso da terra e cobertura vegetal foi convertido para o formato raster e reclassificado de acordo com os pesos de fragilidade de proteção do solo em função do uso da terra e cobertura vegetal. 


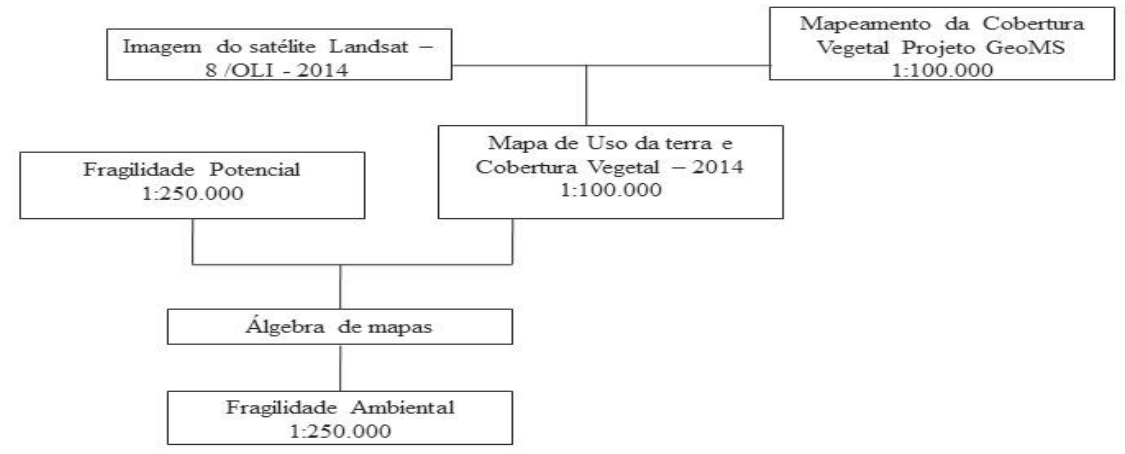

Figura 3 - Fluxograma metodológico para elaboração da fragilidade ambiental.

Fonte: Elaborado pelos autores (2015).

Sendo assim, definiram-se os pesos de fragilidade preconizados em Ross (1994) por critérios quanto à proteção contra erosão e degradação. As áreas de vegetação nativa receberam peso 2 , pois oferecem proteção ao solo contra erosão, porém estão sob forte pressão antrópica em seu entorno, por exemplo, o desmatamento. As áreas de pastagens e silvicultura receberam peso 3, pois apresentam certo grau de proteção ao solo, porém necessitam de melhoramento nos manejos de uso.

Para agricultura conservacionista foi adotado peso 4, pois ela utiliza prática de plantio direto e curvas de nível; e para agricultura convencional, peso 5, por não utilizar essas mesmas técnicas conservacionistas. Para as classes não contidas em Ross (1994) foram atribuídos os seguintes critérios: à área urbana foi atribuído peso 5, pois apresenta pouca ou nenhuma proteção ao solo, sobretudo por se tratar de uma cidade com baixo índice de pavimentação asfáltica, sendo área mais suscetível aos processos erosivos. Já para área úmida e corpos d’água também foi atribuído peso 5, pois são áreas frágeis e que podem ser degradadas caso não sejam realizados manejos de uso de conservação adequados.

Logo em seguida, realizou-se a sobreposição ponderada (álgebra de mapas) no ArcGIS entre o uso da terra, a cobertura vegetal e a fragilidade potencial que resultou na fragilidade ambiental (emergente) da BHRSA. 
Com os mapas de fragilidade ambiental, uso da terra e APP apresentou-se para BHRSA uma proposta de zoneamento ambiental com critérios e recomendações para recuperação de áreas degradadas e indicação do uso da terra. Para elaboração do mapa com as zonas citadas acima, foi realizada a reclassificação do mapa de fragilidade ambiental, de modo a separar as áreas com baixa, média e alta fragilidade, que representam o nível de restrição ao uso da terra. Para os remanescentes florestais e a área urbana, também realizou-se a reclassificação do mapa de uso da terra e cobertura vegetal, de modo a separar esses tipos de uso, indicando as áreas para preservação e conservação da vegetação nativa e áreas para urbanização. As áreas com processos erosivos foram identificadas através de imagens de satélite (Landsat 8, Google Earth pro), trabalho de campo e espacialização por pontos.

As APPs foram identificadas em áreas de nascentes, cursos d'água e de reservatórios artificiais, como estabelece o Código Florestal Brasileiro (BRASIL, 2012). Utilizou-se para definir o tamanho exigido de cada classe de APP (Tabela 3) a ferramenta buffer, cuja técnica cria uma faixa de distância de acordo com a classe de APP encontrada, representando as zonas de restrição legal ao uso (Peluzio; Santos; Fiedler, 2010).

\begin{tabular}{c|c}
\hline \multicolumn{1}{c}{ Classe de APP } & Faixa de APP \\
\hline APP de Nascentes & $50 \mathrm{~m}$ de raio \\
APP marginal de canal com leito até $10 \mathrm{~m}$ de largura & $30 \mathrm{~m}$ \\
APP marginal de canal com leito de $10 \mathrm{~m}$ e $50 \mathrm{~m}$ de largura & $50 \mathrm{~m}$ \\
APP de lagos e reservatórios & $50 \mathrm{~m}$ \\
\hline
\end{tabular}

Tabela 3 - Classes de APP e suas respectivas dimensões.

Fonte: Código Florestal Brasileiro (BRASIL, 2012).

O mapa de APP foi sobreposto ao mapa de uso e recortado, e foram identificadas as áreas que não estão protegidas por vegetação e com algum tipo de uso da terra, ou seja, em desacordo com a legislação. Após todos esses processos, os mapas foram agrupados em apenas um, o qual resultou no mapa de zoneamento ambiental.

Por fim, foram realizados dois trabalhos de campo em fevereiro e setembro de 2015, nos quais foram visitados locais pré-determinados 
em laboratório para visitação; além disso, foram feitas a coleta de pontos amostrais via receptor GNSS e a validação dos resultados de fragilidade.

\section{Resultados e Discussão}

Foram encontrados quatro diferentes graus de fragilidade potencial distribuídos na BHRSA, conforme a Figura 4. A área da planície de inundação foi sobreposta ao mapa de fragilidade potencial. De acordo com a proposta de Ross (2012), a planície de inundação está situada em áreas com declividade de até $2 \%$ próximas aos canais fluviais, cuja fragilidade potencial de inundação é classificada como muito forte.

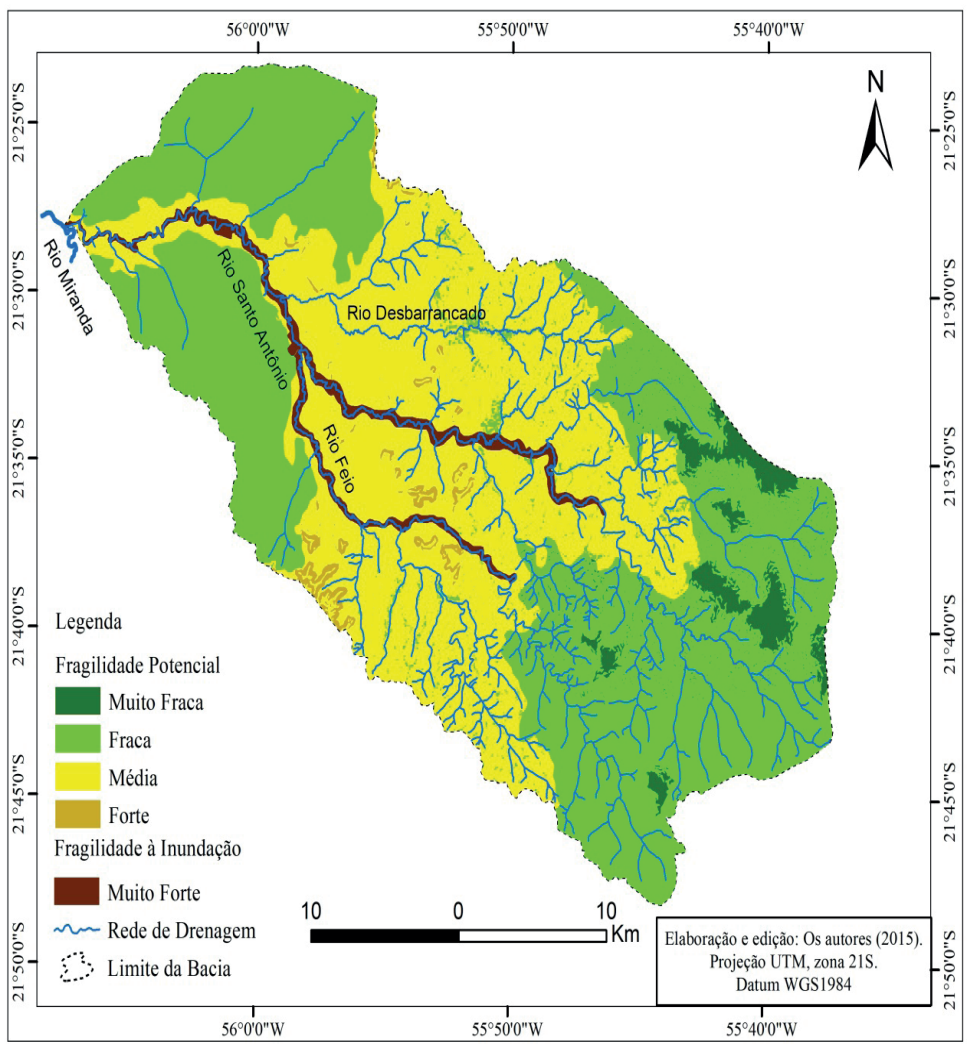

Figura 4 - Mapa de fragilidade potencial.

Fonte: Elaborado pelos autores (2015). 
A fragilidade potencial fraca é a com maior predominância na área, ocupando 50,88\% da bacia, seguida da média, com 41,68\% (Tabela 4). Esses resultados estão associados à presença de solos da classe latossolos encontrados na área, ocorrendo em $53,07 \%$ da área total, cujo peso de fragilidade atribuída foi muito fraco.

\begin{tabular}{c|c|c|}
\hline $\begin{array}{c}\text { Grau de Fragilidade Potencial e Fragilidade de } \\
\text { Inundação }\end{array}$ & Área (km²) & 3,19 \\
\hline Muito Fraca & 38,36 & 50,88 \\
Fraca & 611,6 & 41,68 \\
Média & 501,06 & 1,07 \\
Forte & 12,98 & 3,18 \\
\hline Muito Forte & 38 & 100 \\
\hline Total & 1.202 & \\
\hline
\end{tabular}

Tabela 4 - Quantificação da fragilidade potencial.

Fonte: Elaborado pelos autores (2015).

A declividade influenciou nos resultados, pois a bacia apresenta baixas declividades ( 2 a 15\%), somando $74,62 \%$ da área constituída por áreas de relevo plano e suave ondulado. Resultados similares foram encontrados por Gonçalves et al. (2011) e Oliveira et al. (2012), os fatores solos bem desenvolvidos e baixa declividade são os principais elementos que influenciaram na redução do escoamento superficial, consequentemente atenuando a ocorrência de processos erosivos. A fragilidade potencial de grau muito fraca ocupa 3,19\% da BHRSA, situada no alto curso da bacia em locais de baixa declividade, variando entre 0 e $2 \%$.

A fragilidade potencial forte abrange 1,07\% da área, em terrenos com declividade acentuada entre 15 e $30 \%$ e com solos frágeis como neossolo litólico, neossolo quartzarênico e plintossolo, situados no médio curso da bacia. Devido a essas características físicas, essas áreas apresentam maior fragilidade potencial, favorecendo a ocorrência de processos erosivos de modo natural. Resultados semelhantes foram encontrados por Cabral et al. (2011) e Corte et al. (2015), sendo que áreas com mesmo perfil natural preconizam uma restrição ao uso antrópico. 
Os locais sobre a planície de inundação ocupam 3,18\% da bacia e apresentam condições naturais de fragilidade muito forte, devido aos riscos de inundação. Desse modo, é restrita a ocupação por atividades antrópicas, pois qualquer intervenção acarretará em desequilíbrios ambientais e poderá afetar o sistema hidrológico (Oliveira et al., 2012). Além disso, nesta faixa são encontrados ecossistemas biológicos frágeis, como várzeas e áreas úmidas, que são o habitat de animais silvestres em áreas ripárias (Rodrigues; Gandolfi, 2009).

Para as Áreas Prioritárias para Conservação da Biodiversidade foram encontradas duas classes: muito alta, situada do médio ao alto curso e abrigando áreas com declividade entre 20 e 50\%; e insuficientemente conhecida, que se localiza majoritariamente no baixo curso em áreas planas, sendo que outras estão localizadas no alto curso da bacia, próximo às nascentes.

A classe de prioridade muito alta abrange 55,66\% da bacia; e a insuficientemente conhecida, 44,34\%. Essas áreas são propostas pelo MMA com objetivo de estabelecer diretrizes de zoneamento ambiental sobre o uso de recursos naturais nos biomas brasileiros (Brasil, 2007). Neste sentido, essas divisões são norteadoras para a futura criação de Unidades de Conservação (UC) e Áreas de Proteção Ambiental (APA) que possam conservar e preservar os recursos naturais remanescentes na área da bacia (Pires et al., 2015).

\section{Fragilidade Ambiental}

Os resultados de fragilidade ambiental demonstraram a predominância do nível médio na área, conforme pode ser observado na Figura 5. 


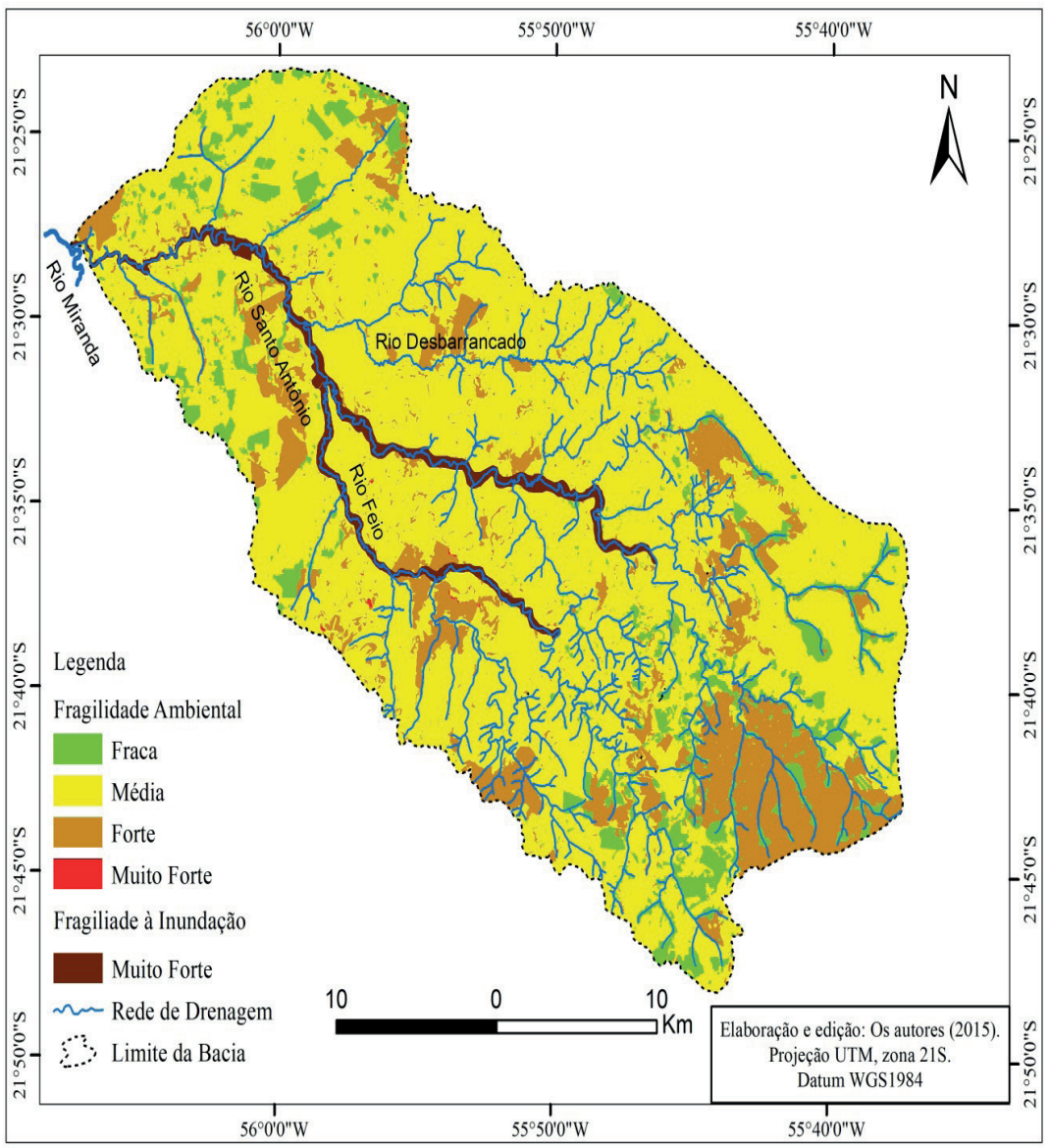

Figura 5 - Mapa de Fragilidade Ambiental.

Fonte: Elaborado pelos autores (2015).

A classe de média fragilidade ambiental ocupa 74,81\% (Tabela 5). Resultados equivalentes a esses também foram constatados por Oliveira et al. (2012) e Corte et al. (2015), demonstrando que fatores de baixa declividade e uso da terra predominante pela pastagem influenciaram o aumento da fragilidade potencial/ambiental. 


\begin{tabular}{c|c|c|}
\hline $\begin{array}{c}\text { Grau de Fragilidade Ambiental e } \\
\text { Fragilidade à Inundação }\end{array}$ & $*$ & $*$ \\
\hline Muito Fraca & 107,43 & 8,93 \\
Fraca & 899,28 & 74,81 \\
Média & 194,92 & 16,23 \\
Forte & 0,37 & 0,03 \\
\hline Muito Forte & 1.202 & 100 \\
\hline Total &
\end{tabular}

Tabela 5 - Quantificação da Fragilidade Ambiental.

* Classe de fragilidade ambiental não encontrada na área de estudo. Fonte: Elaborado pelos autores (2015).

A pastagem ocupa cerca de 52,1\% da área total da bacia, sendo praticada em áreas de relevo plano e ondulado. Nas áreas com declividade mais acentuada, foi observada a utilização de práticas conservacionistas, como sistema de curva de nível, utilizada para diminuir a velocidade do escoamento superficial sobre o solo (Figura 6a). As áreas situadas no alto curso da bacia são utilizadas para agricultura, a qual é subdividida em convencional e conservacionista. Na agricultura conservacionista são utilizados práticas e manejos de controle da erosão dos solos, dentre elas o plantio direto (Figura 6b), cuja área ocupada na bacia é de 12, 57\%.

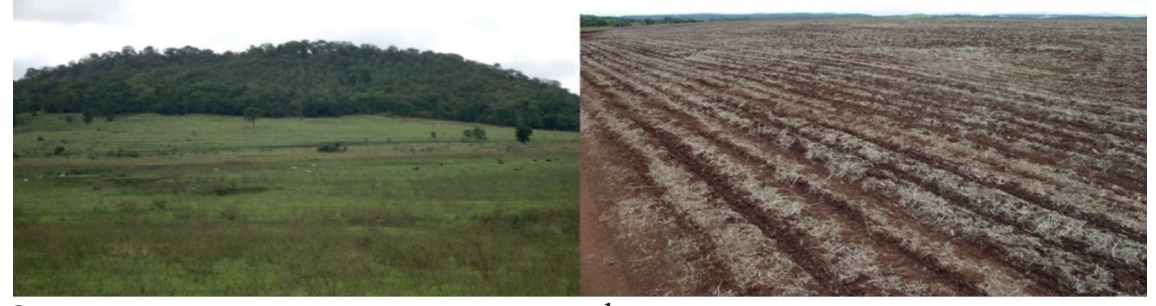

a

b

Figura 6 - Áreas de fragilidade ambiental média: a) Área sob cultivo de pastagem com presença de curvas de nível b) Área onde é praticada agricultura conservacionista com adoção do plantio direto. 
As áreas de fragilidade ambiental forte ocupam 16,23\% da BHRSA, ocorrendo principalmente em áreas utilizadas para a agricultura convencional. Esse tipo de agricultura foi caracterizado por não utilizar práticas conservacionistas, como plantio direto e rotação de culturas, ocupando 8,88 \% da área da bacia. Segundo Botelho e Silva (2011) o sistema de plantio direto apresenta menores perdas de solo, pois o solo permanece coberto pela matéria orgânica que fornece proteção contra escoamento superficial, bem como na reposição de nutrientes no solo.

É possível observar na Figura 7a que o solo encontra-se descoberto e que existem marcas de erosão e remoção de partículas pela água da chuva. Há presença de fragilidade ambiental forte em áreas de sub-bacias dos principais afluentes do rio Santo Antônio, isto é, no rio Feio e no rio Desbarrancado. Nestas duas sub-bacias foram identificados locais com processos erosivos em estágio avançado em áreas de pastagem, algo causado pelo pisoteio por bovinos (Figura 7b e 7c).

a Nesses locais, a presença de neossolo quartzarênico e neossolo litólico eleva a fragilidade para forte, o que favorece o surgimento de processos erosivos em situação de uso intensivo (Abrão et al., 2015). A forte inclinação do relevo favoreceu a classificação de outras áreas com forte fragilidade em áreas com lavouras (Figura 7d). Neste sentido, essas áreas devem ser usadas com cautela, para que o grau de fragilidade não aumente, pois suas características físicas (declividade e solo) favorecem a ocorrência de processos erosivos (Manfré et al., 2013; Bacani; Luchiari, 2014). 


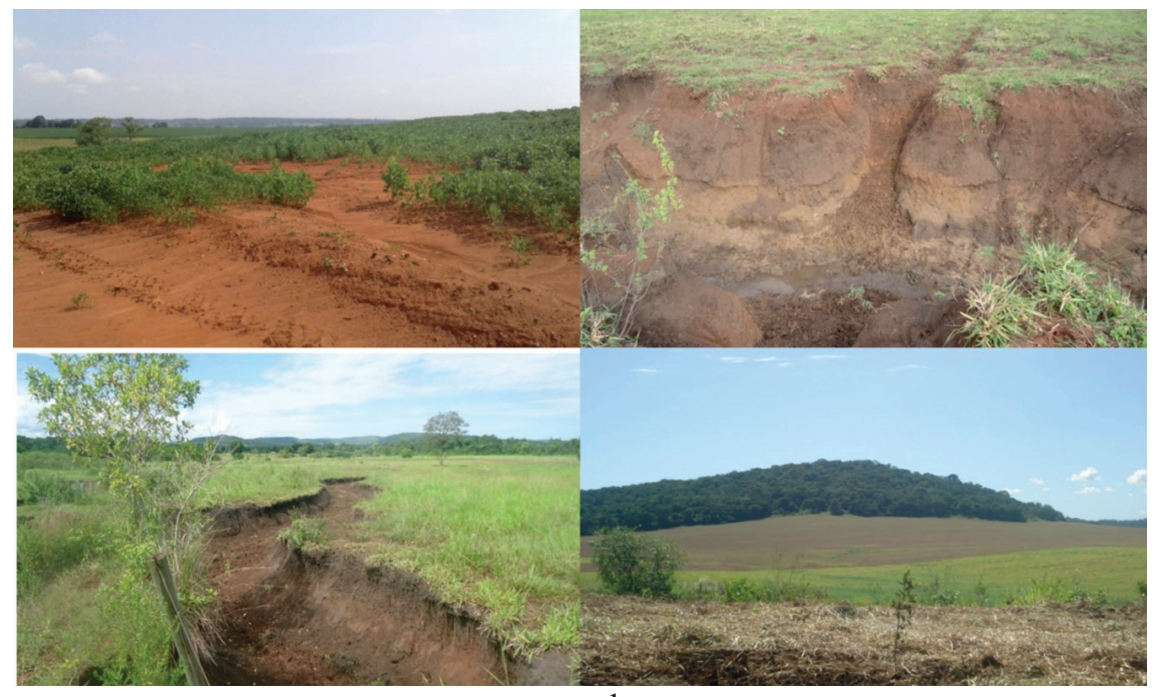

Figura 7 - Áreas com fragilidade ambiental forte. a) Área onde é pratica agricultura convencional com solo descoberto. b) Instauração de erosivo em área de pastagem causado pelo pisoteio de bovinos. c) Voçoroca em área de pastagem em estágio muito avançando. d) Área de encosta (declividade acima de 15\%) usada para agricultura.

Fonte: Elaborado pelos autores (2015).

A classe de fragilidade ambiental muito forte teve pouca ocorrência na bacia, ocupando apenas $0,03 \%$ da área. Esse nível está associado à presença de áreas com declividade alta e muito alta (30 a 50\%), ocupadas por pastagem em áreas de solo com textura arenosa e pouco profunda (Figura 8a). Dessa forma, essas áreas devem ser restritas a qualquer tipo de uso da terra, pois, segundo Guerra (2012), elas são suscetíveis a sofrer danos com erosão e perda de solos e, por isso, devem manter-se preservadas.

As áreas de fraca fragilidade correspondem a 8,93\% e estão situadas em áreas onde há remanescente de cobertura vegetal arbórea, principalmente em áreas de vegetação aluvial e Savana/Floresta Estacional Decidual Submontana (Figura 8b). Resultados similares foram encontrados por Cabral et al. (2011) e Corte et al. (2015) em áreas com remanescentes de cobertura vegetal, a qual oferece maior proteção ao solo, em comparação com outros tipos de uso da terra. 


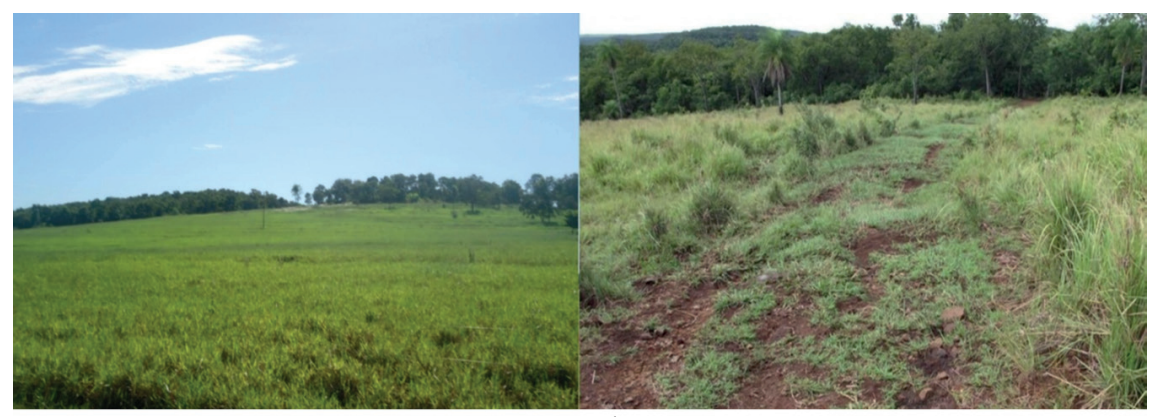

b

Figura 8 - a) Área com muito forte fragilidade devido à declividade acentuada. b) Área de fraca fragilidade em razão da manutenção da cobertura vegetal arbórea nativa.

Fonte: Elaborado pelos autores (2015).

Ressalta-se que em alguns trechos de canais fluviais há ausência de florestas aluviais, que são consideradas Áreas de Preservação Permanente (APPs). Deve-se conservar um tamanho mínimo de vegetação aluvial ao redor de nascentes (raio de 50m) e sobre as margens dos rios, conforme a largura de seu leito (Brasil, 2012). Na BHRSA, identificaram-se irregularidades/incompatibilidades de uso da terra, principalmente nas margens de pequenos rios afluentes do rio Santo Antônio.

Muitos desses pequenos rios estão em áreas circundadas por pastagem e que apresentam média fragilidade ambiental, pois não oferecem a mesma proteção, como a vegetação arbórea, contra erosão e assoreamento dos rios (Figura 9a e 9b). Segundo Campos et al. (2013) a substituição da vegetação pela pastagem causa danos ao solo ao diminuir a sua proteção, tornando-o sujeito a sofrer com a remoção das partículas e lixiviação. 


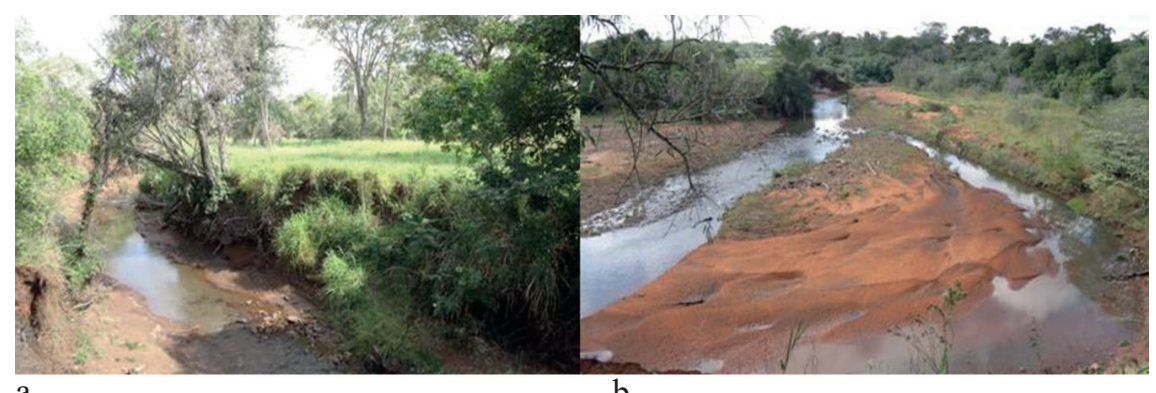

a

b

Figura 9 - Afluentes do rio Santo Antônio com vegetação aluvial totalmente descaracterizada e os rios assoreados. a) Córrego Santa Fé, onde é percebida a ausência total de APP, que foi suprimida para o cultivo de pastagem. b) Rio Desbarrancado fortemente assoreado.

Fonte: Elaborado pelos autores (2015).

Segundo a Agência Nacional de Águas (ANA, 2015), o rio Santo Antônio é responsável por 100\% do abastecimento público de água para a cidade de Guia Lopes da Laguna. Por isso, torna-se ainda mais relevante a preservação da vegetação ciliar das nascentes e dos demais canais. Essa situação de supressão da vegetação ciliar em áreas com média fragilidade ambiental tende a aumentar a fragilidade desses locais, de média para forte ou muito forte, caso não sejam tomadas medidas de regularização da APP ao longo das margens, principalmente dos rios com leito inferior a $10 \mathrm{~m}$ de largura, que formam a maior parte da rede de drenagem, a qual se encontra em situação irregular.

\section{Zoneamento Ambiental}

Com os resultados obtidos através da fragilidade ambiental, identificação de processos erosivos, uso da terra e cobertura vegetal com conflito legal nas APPs, foi possível delimitar as zonas de restrição ao uso, zonas de recuperação e zonas de diferentes usos para BHRSA, conforme pode ser observado na Figura 10. 


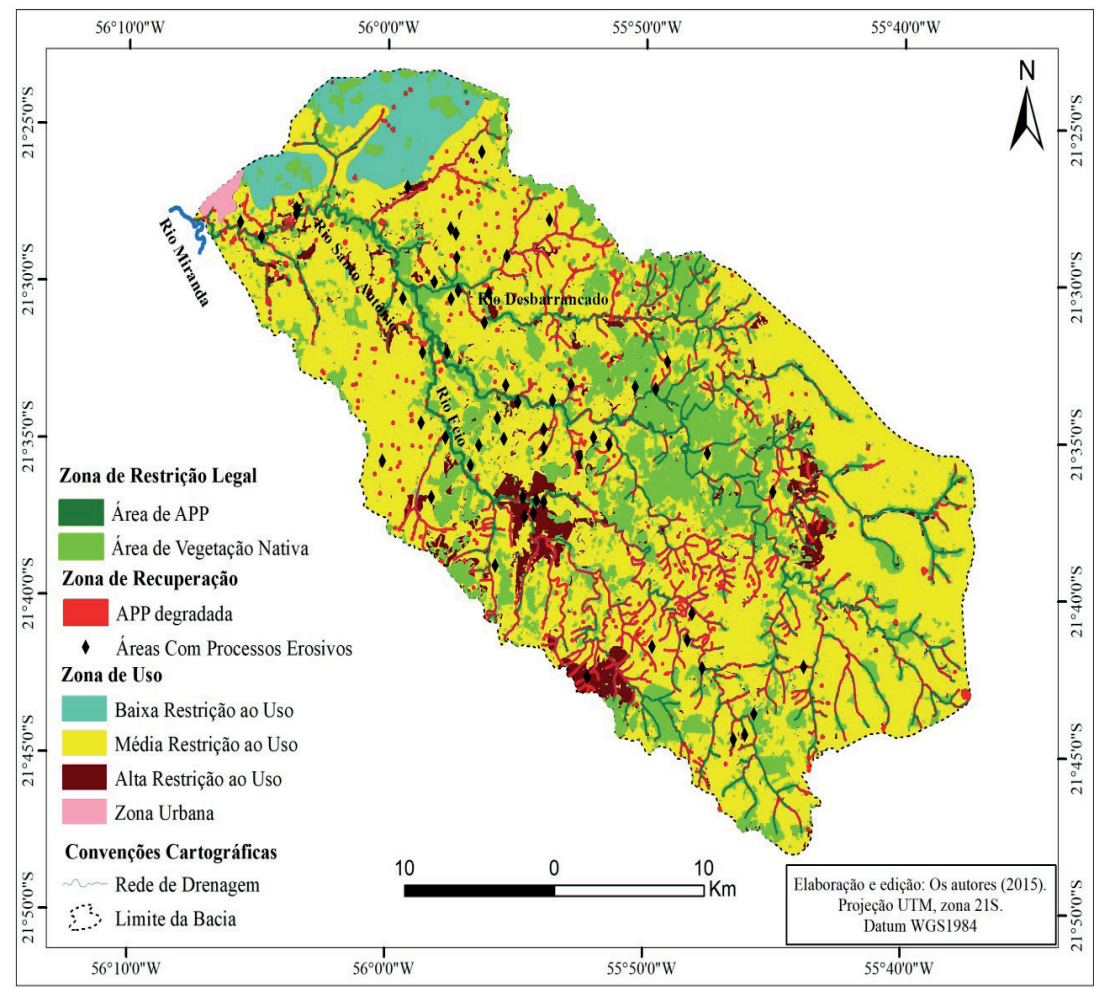

Figura 10 - Mapa de Zoneamento Ambiental.

Fonte: Elaborado pelos autores (2015).

Para elaboração do Zoneamento Ambiental, foram utilizados os resultados de fragilidade ambiental, uso da terra e cobertura vegetal e conflitos de uso com as APPs, no qual se estabeleceram critérios para as zonas de uso propostas e recomendações que devem ser implementadas em um planejamento e gestão ambiental do local, conforme pode ser observado no Quadro 2. 


\begin{tabular}{|c|c|c|}
\hline Zona & Critérios & Recomendações \\
\hline $\begin{array}{l}\text { Zona de restrição/ área com } \\
\text { vegetação nativa. }\end{array}$ & $\begin{array}{l}\text { APP; } \\
\text { reserva legal; remanescentes florestais. }\end{array}$ & Preservação e conservação. \\
\hline Zona de recuperação de APP. & APP em conflito com uso da terra. & $\begin{array}{l}\text { Recuperação por meio de } \\
\text { reflorestamento. }\end{array}$ \\
\hline $\begin{array}{c}\text { Zona de recuperação com } \\
\text { processos erosivos. }\end{array}$ & $\begin{array}{l}\text { Áreas com processos erosivos (ravinas } \\
\text { e voçorocas). }\end{array}$ & $\begin{array}{l}\text { Recuperação por meio de técnicas de } \\
\text { obliteração de processos erosivos; } \\
\text { adoção de práticas conservacionistas. }\end{array}$ \\
\hline Zona de baixa restrição ao uso. & $\begin{array}{l}\text { Áreas com declividade } 0 \text { a } 15 \% ; \\
\text { com presença de latossolos; } \\
\text { potencial de erosão e fragilidade } \\
\text { ambiental baixa. }\end{array}$ & $\begin{array}{l}\text { Uso agrícola e adoção de práticas } \\
\text { conservacionistas e manejo de } \\
\text { pastagens. }\end{array}$ \\
\hline $\begin{array}{l}\text { Zona de média restrição ao } \\
\text { uso da terra. }\end{array}$ & $\begin{array}{l}\text { Áreas com declividades de } 15 \text { a } 30 \% ; \\
\text { potencial a erosão e fragilidade } \\
\text { ambiental média. }\end{array}$ & $\begin{array}{l}\text { Uso por pastagens com adoção de } \\
\text { práticas conservacionistas (curva de } \\
\text { nível) com baixo pisoteio. }\end{array}$ \\
\hline $\begin{array}{l}\text { Zona de alta restrição ao uso } \\
\text { da terra. }\end{array}$ & $\begin{array}{c}\text { Áreas com declividade }>30 \% \\
\text { neossolos litólicos e quartzarênico; } \\
\text { plintossolo; potencial de erosão e } \\
\text { fragilidade ambiental forte ou muito } \\
\text { forte. }\end{array}$ & $\begin{array}{l}\text { Manutenção da cobertura vegetal } \\
\text { nativa ou reflorestamento com } \\
\text { espécies nativas de uso sustentável. }\end{array}$ \\
\hline Zona Urbana. & Cidade de Guia Lopes da Laguna. & $\begin{array}{l}\text { Expansão urbana em sentido norte } \\
\text { e não apta para o sul, leste e oeste, } \\
\text { onde estão localizadas as planícies de } \\
\text { inundação. }\end{array}$ \\
\hline
\end{tabular}

Quadro 2 - Propostas de zoneamento ambiental para BHRSA.

Fonte: Elaborado pelos autores (2015).

Nas áreas destinadas à zona de restrição legal, estão enquadradas as APPs, conforme determina o código florestal brasileiro (Brasil, 2012). Os remanescentes de vegetação nativa foram incluídos nessa categoria, áreas de vegetação típicas dos biomas Cerrado e Mata Atlântica, cujas áreas foram suprimidas e fragmentadas pelo avanço da pastagem e agricultura nos últimos anos. Do ponto de vista biológico, essas áreas de vegetação nativa desempenham um importante papel para fauna, pois formam corredores ecológicos ao permitirem a circulação de animais em grandes áreas, devendo, portanto, estar conectadas entre si (Martins, 2007). Segundo Manfré et al. (2013) essas áreas auxiliam na dinâmica do equilíbrio ecológico de bacias hidrográficas, especialmente na conservação da biodiversidade e proteção do solo contra erosão. 
As zonas de recuperação de APP têm por objetivo o restabelecimento desses corredores ecológicos, principalmente entre as APPs e a vegetação nativa. Mais da metade das APPs da BHRSA encontram-se em conflito com algum tipo de uso da terra, principalmente nos pequenos rios (com leito de até $10 \mathrm{~m}$ de largura) localizados no médio curso, onde há grandes remanescentes de vegetação nativa (Savana/Floresta Estacional Decidual Submontana). Para a recuperação dessas áreas, propõe-se o seu isolamento das demais áreas, e, no caso das APPs, a recuperação de acordo com o Código Florestal Brasileiro (Brasil, 2012), com plantio de espécies arbóreas nativas.

A zona de recuperação com processos erosivos encontra-se em áreas de média fragilidade ambiental e com uso pela pastagem sem observação das práticas conservacionistas, com superlotação de animais por hectares (ha) e forte pisoteio próximo aos canais fluviais e áreas íngremes. Para reverter esse quadro de degradação, é recomendado o uso de técnicas para obliteração de processos erosivos, o que envolve uma descrição detalhada de solo, o tipo de uso que está sendo empregado na área e a adoção de práticas conservacionistas para mitigar os processos. Para essa zona, de recuperação, deverá ser dada atenção maior, pois caso as recomendações não sejam adotadas, o quadro tende a se agravar nos próximos anos.

As zonas de baixa restrição ao uso da terra são aquelas destinadas à exploração agrícola e pastagem, compreendendo áreas com baixa declividade e solos bem desenvolvidos, com resultados de fragilidade ambiental fraca. Neste sentido, áreas com uso da agricultura convencional sem adoção de práticas de manejo e controle de erosão devem ser revistas, pois apresentam riscos de perda de solos, podendo aumentar o grau de fragilidade ambiental para forte e muito forte.

A zona de média restrição ao uso da terra é ocupada por pastagem situada em áreas com declividade média e alta (15 a 30\%) e solos frágeis. Nessas áreas predomina o grau de fragilidade ambiental média associado à pastagem, que, por sua vez, oferece proteção ao solo quando manejada adequadamente. Entretanto, essas áreas devem ser monitoradas continuamente, pois existem alguns pontos com erosão causada pelo pisoteio do gado e a maior parte das APPs em conflitos com uso da terra encontra-se nessas áreas, podendo elevar o grau de fragilidade ambiental futuramente. 
A zona de alta restrição ao uso da terra foi enquadrada nas áreas com declividades superiores a 30\% e com solos muito frágeis, compreendendo áreas sensíveis à ocupação antrópica. Nesses locais predomina a fragilidade ambiental forte e muito forte, com declividade acentuada e ocupada por pastagem e pequenas áreas com agricultura convencional, que não adota práticas conservacionista. O difícil acesso à mecanização agrícola e solos de baixa produtividade tornam-se condicionantes à alta restrição do uso antrópico. Sendo assim, recomendam-se a manutenção das áreas com vegetação nativa (topo de morros) e a recomposição da cobertura vegetal nativa nas áreas em que ela não está mais presentes e/ou interligada com outros fragmentos de vegetação (APP).

Na zona urbana, está inserida parcialmente a cidade de Guia Lopes da Laguna, em áreas de baixa declividade e com presença de latossolos, o que a torna uma área propícia à ocupação. Porém existem ocupações irregulares na APP da margem direita do rio Santo Antônio que estão sujeitas a sofrerem com inundações e desastres ambientais, além de oferecerem riscos às pessoas que ali moram. Recomenda-se a remoção dessas pessoas para áreas seguras, distantes da planície de inundações, para que ocupem áreas mais seguras, de maneira ordenada e planejada, situadas no sentido norte da cidade, cujas características físicas apresentam boas condições à expansão urbana de modo planejado. Ressalta-se também que em muitos trechos de ruas na cidade ainda não há nenhum tipo de pavimentação e, por isso, esses são locais em que podem surgir processos erosivos, caso não sejam executadas obras de escoamento de drenagem.

\section{Considerações Finais}

Os resultados indicaram um predomínio da classe de média fragilidade, o que significa que se deve ficar atendo à maneira como os recursos naturais estão sendo explorados, principalmente em áreas com declividade acentuada em solos rasos em processo de formação, como os neossolos. Essas áreas estão situadas no médio curso e são utilizadas principalmente por pastagem e agricultura convencional.

Foram feitas recomendações quanto à adoção de práticas conservacionistas e à necessidade da recuperação de áreas degradadas, pois caso isso não ocorra o nível de fragilidade ambiental tende a aumentar. Sendo assim, com o aumento da fragilidade poderá haver um 
comprometimento na qualidade ambiental dos recursos naturais e sua exaustão, com destaque para a água que abastece a população de Guia Lopes da Laguna.

Ressaltam-se o uso das técnicas de geoprocessamento como ferramenta e os dados de sensoriamento remoto que permitiram uma análise integrada dos elementos naturais e antrópicos. Os produtos cartográficos elaborados permitiram diagnosticar a fragilidade ambiental e subsidiar propostas de zoneamento ambiental preliminar com vista ao ordenamento territorial da BHRSA.

\section{Agradecimentos}

À Coordenação de Aperfeiçoamento de Pessoal de Nível Superior (CAPES) pela concessão da bolsa de Mestrado junto ao Programa de PósGraduação em Geografia da Universidade Federal de Mato Grosso do Sul (UFMS) - Campus de Aquidauana (CPAq).

\section{Referências}

ABRÃO, C. M.R.;FERNANDES, E.F.L.;BACANI, V.M. SILVA, J.F. Geoechnologies applied to mapping of environmental fragility in the Desbarrancado river basin, MS. Geografia, Rio Claro. v. 40, número especial, p. 9-26, ago. 2015.

AGÊNCIA NACIONAL de ÁGUAS (ANA). Disponível em: http://www2.ana.gov. br/Paginas/default.aspx>. Acesso em: 10 de jun. de 2015

BACANI, V. M.; LUCHIARI, A. Geoprocessamento aplicado ao zoneamento ambiental da bacia hidrográfica do alto rio Coxim - MS. GEOUSP - Espaço e Tempo, São Paulo, v. 18, n. 1, p. 184-197, abr. 2014.

BOTELHO, R. G. M.; SILVA, A. S. Bacia hidrográfica e qualidade ambiental. In: Vitte, A. C.; Guerra, A. J. T. Reflexões sobre a geografia física no Brasil. 5. ed. Rio de Janeiro: Bertrand Brasil. 2011. p. 153-192.

BRASIL. Lei $\mathrm{n}^{\circ}$ 12.651, de 25 de maio de 2012. Dispõe sobre a proteção da vegetação nativa; altera as Leis nos 6.938, de 31 de agosto de 1981, 9.393, de 19 de dezembro de 1996, e 11.428, de 22 de dezembro de 2006; revoga as Leis nos 4.771, de 15 de setembro de 1965, e 7.754, de 14 de abril de 1989, e a Medida Provisória no 2.166-67, de 24 de agosto de 2001; e dá outras providências. Brasília, 2012. $34 \mathrm{p}$.

. Ministério do Meio Ambiente. Áreas Prioritárias para a conservação, uso sustentável e repartição de benefícios da biodiversidade brasileira: atualização portaria MMA n ${ }^{\circ}$ 09, de 23 de janeiro de 2007. Brasília. 2007. 300 p. 
CÂMARA, G.; SOUZA, R. C. M.; FREITAS, U. M.; GARRIDO, J. C. P. SPRING: integratingre motes ensing and GIS by object-oriented data modelling. Computers \& Graphics, v. 20, p. 395-403, 1996.

CABRAL, J. B. P.; ROCHA, I. R.; MARTINS, A. P.; ASSUNÇÃO, H. F.; BECEGATO, V. A. Mapeamento da fragilidade ambiental da bacia hidrográfica do rio Doce (GO), utilizando técnicas de geoprocessamento. GEOFOCUS, Barcelona, n. 11, p. 51-69, jan. 2011.

CAMPOS, S.; SILVEIRA, G. R. P. da.; PISSARRA, T. C. T.; FELIPE, A. C. Diagnóstico do uso do solo em APP na microbacia do córrego Santo Antonio - São Manuel (SP) em fincão da legislação ambiental. Geoaraguaia, Barra do Garças-MT, v. 3, n. 2, p. 198-2010, ago. 2013.

CONGALTON, R. G. A review of assesing the accuracy of classifications of remotely sensed data. Remote Sens. Environ., v. 47, p. 35-46, 1991.

CORTE, A. P. D.; HENTZ, Â. M. K.; DOUBRAWA, B.; SANQUETTA, C. R. Environmental fragility of Iguaçu river watershed, Paraná, Brasil. BOSQUE, Valvidia, v. 36, n. 2, p. 287-297, 2015.

CREPANI, E.; MEDEIROS, J. S.; FILHO, P. H.; FLORENZANO, T. G.; DUARTE, V.; BARBOSA, C. C. Sensoriamento remoto e geoprocessamento aplicados ao Zonemento Ecológico Econômico e ao ordenamento territorial. São José dos Campos: INPE, 2001. 103 p.

EMPRESA BRASILEIA DE PESQUSIA AGROPECUÁRIA (EMBRAPA). Série histórica de dados de pluviosidade no MS. Disponível em: <http://www.cpao. embrapa.br/clima/clima.cpao/index.php?pg=chuvams>. Acesso em: 20 maio 2014.

ESRI. Environmental Systems Research Institute. ArcGis10.2 Copyright ESRI Inc. 2013.

FERREIRA, C. C.; PIROLI, E. L. Zoneamento Ambiental das Paisagens: estudo de caso do Alto Curso da Bacia Hidrográfica do rio Sucuriú Mato Grosso do Sul, Brasil. Boletim Goiano de Geografia, Goiânia, v. 36, n. 2, p. 341-358, maio/ago. 2016.

FLORENZANO, T. G. Iniciação em sensoriamento remoto. 3. ed. São Paulo: Oficina de textos, 2011. $128 \mathrm{p}$. textos, 2002. $97 \mathrm{p}$.

Imagens de satélite para estudos ambientais. São Paulo: Oficina de GONÇALVES, G. G. G.; DANIEL, O.; COMUNELLO, É.; VITORINO, A. C. T.; ARAI F. K. Determinação da fragilidade ambiental de bacias hidrográficas. FLORESTAS, Curitiba, v. 41, n. 4, p. 797-808, out./dez. 2011.

GUERRA, A. J. T. Processos Erosivos nas Encostas In: GUERRA, A. J. T.; CUNHA, S. B. Geomorfologia: uma atualização de bases e conceitos. 11. ed. Rio de janeiro: Bertrand Brasil, 2012. p. 149-209.

IBGE. Instituto Brasileiro de Geografia e Estatística. Manual Técnico de uso da terra. 3. ed. Rio de Janeiro: IBGE, 2013. 171 p. 
JENSEN, J. R. Sensoriamento remoto do ambiente: uma perspectiva em recursos terrestres. São José dos Campos: Parênteses, 2009. 599 p.

KAWAKUBO, F. S.; MORATO, R. G.; CAMPOS, K. C.; LUCHIARI, A.; ROSS, J. L. S. Caracterização empírica da fragilidade ambiental utilizando geoprocessamento. In: SIMPÓSIO DE SENSORIAMENTO REMOTO, 12., 2005, Goiânia. Anais... Goiânia: INPE, 2005. p. 2205-2210.

LANDIS, J. R.; KOCH, G.G. The measurement of observer agreement for categorical data. Biometrics, v. 33, n. 1, p. 159-174, 1977.

MANFrÉ, L. A.; SILVA, A. M.; URBAN, R. C.; RODGERS, J. Environmental Fragility evaluation and guidelines for environmental zoning: a study case on Ibiuna (the Southeastern Brazilian region). Environ. Earth Sci., v. 69, p. 947-957, maio/ago. 2013.

MARTINS, S. V. Recuperação de Matas Ciliares. 2. ed. Viçosa, MG: CPT, 2007. $255 \mathrm{p}$.

MATO GROSSO DO SUL (Estado). Secretaria de Planejamento e Coordenação Geral. Macrozoneamento geoambiental do Estado de Mato Grosso do Sul. Campo Grande: SEPLAN, 1989. 242 p.

MOREIRA, M. A. Fundamentos do sensoriamento remoto e metodologias de aplicação. 3. ed., 1. reimp. Viçosa: Ed. da UFV, 2007. 320 p.

NOVO, E. M. L. M. Sensoriamento Remoto: princípios e aplicações. 4. ed. São Paulo: Blucher, 2010. 387 p.

OLIVEIRA, R. G.; BACANI, V. M, SILVA, V. R.; CUNHA, E. R.; FERREIRA, E. M. Análise da fragilidade ambiental da bacia hidrográfica do córrego São JoãoMS utilizando geoprocessamento. Revista Brasileira de Cartografia, v. 1, n. 64, p. 15-24, fev. 2012.

PELUZIO, T. M. de. O.; SANTOS, A. R. dos; FIEDLER, N. C. (Org.). Mapeamento de áreas de preservação permanente no ArcGIS 9.3. Alegre: CAUFES, 2010. 58 p. PIRES, L. C.; SILVA, L. F.; MENDONÇA, B. G.; BACANI, V. M. Análise da fragilidade ambiental do município de Aquidauana-MS. Caderno de Geografia, Belo Horizonte, v. 25, n. 43, p. 52-65, jan./jun. 2015.

RODRIGUES, R. R.; GANDOLFI, S. Conceitos, tendências e ações para a recuperação de florestas ciliares In: RODRIGUES, R. R.; LEITÃO-FILHO, H. F. (Org.). Matas ciliares: conservação e recuperação. 2. ed., 2. reimp. São Paulo: Fapesp, 2009. p. 235- 247.

ROSS, J. L. S. Land forms and environmental planning: potentialities and fragilities. Revista do Departamento de Geografia, FFLCH/USP, São Paulo, Volume Especial 30 anos RDG, p. 38-51, 2012.

Análise empírica da fragilidade ambiental dos ambientes naturais e antropizados. Revista do Departamento de Geografia, FFLCH/USP, São Paulo, p. 63-74, fev. 1994.

SANTOS, R. F. dos. Planejamento ambiental: teoria e prática. São Paulo: Oficina de Textos, 2004.184 p. 
SILVA, J. S. V.; POTT, A.; ABDON, M. M.; POTT, V. J.; SANTOS, K. R. Projeto GeoMS: Cobertura vegetal e uso da terra do Estado de Mato Grosso do Sul. Campinas: Embrapa Informática Agropecuária, 2011. 64 p.

SISTEMA INTERATIVO DE SUPORTE AO LICENCIAMENTO $\bar{A} \bar{M} \bar{B} \bar{I} E N T A L \quad$ (SISLA). Disponível em: <http://sisla.imasul.ms.gov.br/sisla/ pagina_inicial.php> Acesso em: 11 maio 2014.

TRICART, J. Ecodinâmica. Rio de Janeiro: IBGE, 1977. 91 p.

U.S. GEOLOGICAL SURVEY (USGS). Earth Explorer USCG Science for a Changing World. Disponível em: <http://earthexplorer.usgs.gov/>. Acesso em: 14 abr. 2014.

VALERIANO, M. M. TOPODATA: guia de utilização de dados geomorfométricos locais. São Jose dos Campos: INPE, 2008. 44 p.

Cleiton Messias Rodrigues Abrão - Doutorando em Geografia pela Universidade Federal da Grande Dourados, Faculdade de Ciências Humanas. Mestre em Geografia pela Universidade Federal de Mato Grosso do Sul, campus de Aquidauana. ORCID: https://orcid.org/0000-0003-1928-6769

Vitor Matheus Bacani - Doutor em Geografia Física pela Universidade de São Paulo. Mestre em Geografia pela Universidade Federal de Mato Grosso do Sul, campus de Aquidauana. Atualmente é professor efetivo do curso de geografia da Universidade Federal de Mato Grosso do Sul, campus de Três Lagoas, e orienta nos programas de pós-graduação em geografia da UFMS em Aquidauana e Três Lagoas, e em recursos naturais em Campo Grande. ORCID: https://orcid.org/0000-0002-8650-0780

\section{Contribuição dos autores}

Os dois autores ofereceram substanciais contribuições científicas e intelectuais ao estudo. O primeiro autor desenvolveu a pesquisa bibliográfica, trabalho de campo e produção dos mapas. O segundo autor foi responsável pelas correções e considerações sobre a produção dos dados e resultados da pesquisa. 